\title{
Impact of Botox-A SNAP-25 protein expression and the mechanism of inhibitory neurotransmitter imbalance in chronic sciatic nerve pain rat model
}

\author{
XU-DONG DING $^{1 *}$, WEI WANG ${ }^{2 *}$, ZHI-GANG DING $^{1}$, YAN-PING LIU ${ }^{1}$, JING ZHONG $^{2}$ and HUA-XIAN CHEN ${ }^{1}$ \\ Departments of ${ }^{1}$ Rehabilitation and ${ }^{2}$ Ultrasound Imaging, Xiangyang No. 1 People's Hospital, \\ Hubei University of Medicine, Xiangyang, Hubei 441000, P.R. China
}

Received July 8, 2016; Accepted March 16, 2017

DOI: $10.3892 /$ etm.2017.4351

\begin{abstract}
The Botox-A impact on the expression of SNAP-25 protein in rat chronic sciatic nerve pain model was assessed and the mechanism of inhibitory neurotransmitter imbalance was studied. A chronic constriction injury (CCI) model consisted of 30 healthy male rats. The rats were randomly divided into the sham-operated group, CCI group and BoNT/A intervention group, and during 1, 7 and 14 days we conducted mechanical withdrawal threshold (MWT) test and thermal withdrawal latency (TWL) test before and after operation. After 14 days, the animals were sacrificed. SNAP-25 protein expression level, mRNA subunit NR2B within excitatory neurotransmitter glutamate GLT and protein expression level, as well as GAT mRNA, the inhibitory GABA neurotransmitter transporter and protein expression level were studied by RT-polymerase chain reaction and western blot analysis. The difference between MWT and TWL at each point in time before and after operation showed no statistical significance $(\mathrm{P}>0.05)$ in the sham-operated group. For the CCI group at each time point, MWT and TWL were obviously lower than the sham-operated group and the difference was statistically significant $(\mathrm{P}<0.05)$ while the internal difference at each time point showed no statistical significance $(P>0.05)$. The expression level of protein of SNAP-25 and NR2B mRNA in the CCI group was clearly higher than sham-operated group. Additionally, the expression level of GAT-1 mRNA
\end{abstract}

Correspondence to: Dr Hua-Xian Chen, Department of Rehabilitation, Xiangyang No. 1 People's Hospital, Hubei University of Medicine, 15 Jiefang Road, Xiangyang, Hubei 441000, P.R. China E-mail: chen_huaxian1@163.com

${ }^{*}$ Contributed equally

Key words: Botox-A, chronic sciatic nerve pain, SNAP-25, mechanical withdrawal threshold, heat pain threshold, excitatory neurotransmitter glutamate GLT, GAT mRNA the inhibitory GABA neurotransmitter transporter and protein in CCI group was apparently lower than the sham-operated group. In conclusion, Botox-A helped reduce SNAP-25 within rat chronic sciatic nerve pain model thereby relieving pain.

\section{Introduction}

Neuropathic pain (NPP) is the pain caused by the injury of a nerve, common in shingles, diabetes and cancer, manifested as a chronic, persistent symptom and seriously affecting the quality of life of patients (1). The relieve effects of anti-epileptic drugs and NSAIDs are limited (2). The effect of nerve damage is possible to clear short-term, but it easily relapse and has poor therapeutic effect in second treatment (3). Opioids have a strong analgesic effect, but could easily cause addiction and drug dependence (4). Hyperalgesia, allodynia and spontaneous pain are three characteristics of NPP (5), and the transmission of pain signals in the central nervous system is completed through releasing and clearing neurotransmitters, where the process is continuous and precise. The formation of SNARE complex is the main component that affects the release of a transmitter which is one of three proteins of the compound and useful in regulating the release of neurotransmitter (6). Clearance of transmitter depends on the specific transporters such as excited neurotransmitter glutamate transporter GLT and inhibition of GABA transporter GAT-1 (7). The production of NPP may be related to the excessive activation of excitatory transmitters and the loss of inhibitory transmitters (excitatory inhibition imbalance) (8).

Botox is produced by a Gram-positive anaerobic bacillus Clostridium botulinum and is known as the most powerful analgesic active substance. Thus, BoNT/A could decompose SNAP-25 from the SNARE protein super-family in atopic (9). In various pain models, the use of very low doses of BoNT/A in peripheral or central system significantly relieved pain and improved related behavior. Compared to traditional treatment, Botox has the advantages of exact effect and working long time after a single dosage (10).

Based on the above reasons, the present study further analyzed the Botox-A impact on the expression of protein SNAP-25 in rat chronic sciatic nerve pain model and studied the mechanism of inhibitory neurotransmitter imbalance. 


\section{Materials and methods}

\section{Experimental material}

Animals. Thirty SPF grade purebred healthy adult male Sprague-Dawley rats weighing 200-250 g were purchased from the Experimental Animal Department of Central South University.

Chronic constriction injury (CCI) model. Referring to methods of Bennett's methods (11), we used abdominal chloratehydrate anesthesia and exposed the sciatic nerve. Then, using nerve dissector the nerve stem at both ends was severed; 4-0 chromic catgut was used and the main stem was ligatured. The sciatic nerve compression was detected through $\mathrm{x} 6$ dissecting microscope, which showed that blood vessels on the surface of the nerve stem were mildly pressed but the blood flow was not interrupted. The same method was used for ligature 4 surgery knots with $1 \mathrm{~mm}$ intervals. This is called the CCI model. Thus, the wound was washed, and sutured layer by layer, to proceed with intramuscular injection of penicillin to prevent infection, and monitor vital signs.

Catheter in lumbar sheath. We used the prone position, L4-5, and a midline longitudinal incision of $\sim 1 \mathrm{~cm}$ in length, then exposed subcutaneous tissue layer by layer bluntly, locating the center of the intervertebral space and gently pulling up L4 spinous process with a hemostat and exposing L4-5 clearly. The PF 0503 catheter was slowly placed with the guidance of spinal needle core to the head along with the spinal needle core. After removing the inner core, silvery cerebrospinal fluid flows out from the catheter.

Three days later, rats with normal bowel movement and without movement disorders were selected to test the effect of catheter in lumbar sheath using catheterization lidocaine.

Grouping. The samples were randomly divided into the sham-operated group, CCI group and BoNT/A intervention group each with 10 rats. The sham-operated and CCI groups were injected with $20 \mu \mathrm{l}$ normal saline through intrathecal injection, while BoNT/A intervention group was treated with 0.01 units intrathecal injection dissolved in $10 \mu 1$ saline and $10 \mu 1$ saline washing pipe. Mechanical withdrawal threshold (MWT) and thermal withdrawal latency (TWL) were detected before and after surgery 1, 7 and 14 days, and after 14 days, the rats were sacrificed. Using RT-polymerase chain reaction (PCR) and western blot analysis, the intumescentia lumbalis of the spinal cord was tested for SNAP-25 and protein expression level, mRNA, the subunit NR2B within excitatory neurotransmitter glutamate GLT and protein expression level; as well as GAT mRNA, the inhibitory GABA neurotransmitter transporter and protein expression level.

$R T-P C R$. A variety of methods were collaboratively used: spinal cord segment specimens were taken in a standard manner, the total RNA was extracted using TRIzol reagent to detect concentration, purity and integrity, and the results were analyzed as follows: Reverse transcribed cDNA, primer design (Table I), the reaction system (cDNA $1 \mu \mathrm{l}+10 \mu \mathrm{M}$ upstream and downstream primers $1 \mu l+2 \mathrm{X}$ Taq Master Mix increasing 12.5-25 $\mu \mathrm{l}$ through adding water), the reaction conditions
Table I. Primer design.

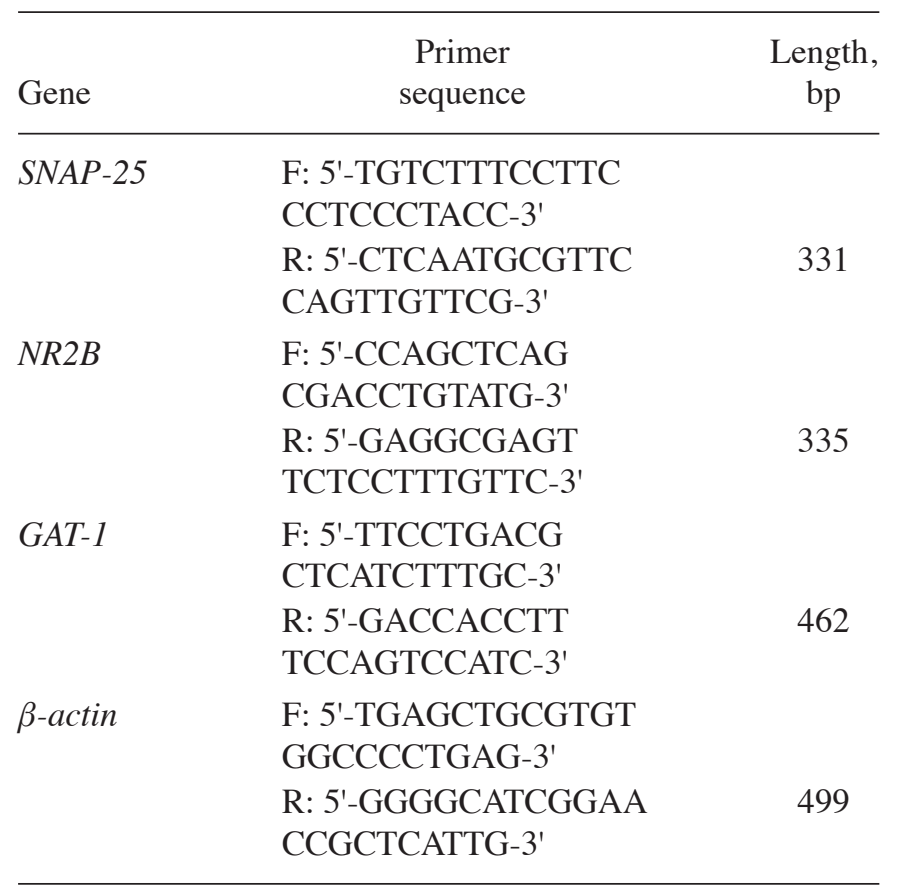

(Table II), the product of electrophoresis, the removal of the gel and capturing of images on the imaging system. Finally, integral optical density of each strip value was read from the image analysis software GelAnalyzer 2010a (University of Leicester, London, UK).

Western blot analysis. Lysis buffer was used to extract total protein and the BCA method was applied for the detection of the protein concentration. Rabbit polyclonal SNAP-25 antibody (dilution, 1:500; cat. no. ab5666), rabbit polyclonal NR2B antibody (dilution, 1:500; cat. no. ab65783), rabbit polyclonal GAT-1 antibody (dilution, 1:500; cat. no. ab426) and rabbit polyclonal GAPDH antiboody (dilution, 1:500; cat. no. ab37168) were purchased from Abcam (Cambridge, MA, USA). Secondary goat anti-rabbit (HRP) IgG antibody (dilution, 1:2,000; cat. no. ab6721; Abcam) was added and agitated for $1 \mathrm{~h}$ at room temperature, stained and exposed using Gd-pro 4.0 image analysis system to study protein bands.

Statistical analysis. SPSS 19.0 statistical software (SPSS, Inc., Chicago, IL, USA) was used to log data and analysis. Quantitative data are expressed as mean \pm standard deviation. $\mathrm{T}$ was applied for test among different groups, while analysis of variance was used for repeated measures within each group. $\mathrm{P}<0.05$ was considered to indicate a statistically significant difference.

\section{Results}

Comparison between $M W T$ and TWL. For the sham-operated group, the difference between MWT and TWL at each time point before and after operation showed no statistical significance $(\mathrm{P}>0.05)$. In the $\mathrm{CCI}$ group at each time point, MWT and TWL were obviously lower than the sham-operated group and the difference was statistically significant $(\mathrm{P}<0.05)$ 
Table II. RT-polymerase chain reaction condition.

\begin{tabular}{llcrl}
\hline Gene & Variance & Circulation & Cycle no. & Extension \\
\hline$S N A P-25$ & $94^{\circ} \mathrm{C} 2 \mathrm{~min}$ & $94^{\circ} \mathrm{C} 30 \mathrm{sec}, 56^{\circ} \mathrm{C} 30 \mathrm{sec}, 72^{\circ} \mathrm{C} 30 \mathrm{sec}$ & 30 & $72^{\circ} \mathrm{C} 2 \mathrm{~min}$ \\
$N R 2 B$ & $94^{\circ} \mathrm{C} 2 \mathrm{~min}$ & $94^{\circ} \mathrm{C} 30 \mathrm{sec}, 57^{\circ} \mathrm{C} 30 \mathrm{sec}, 72^{\circ} \mathrm{C} 30 \mathrm{sec}$ & $72^{\circ} \mathrm{C} 2 \mathrm{~min}$ \\
$G A T-1$ & $94^{\circ} \mathrm{C} 2 \mathrm{~min}$ & $94^{\circ} \mathrm{C} 30 \mathrm{sec}, 56^{\circ} \mathrm{C} 30 \mathrm{sec}, 72^{\circ} \mathrm{C} 30 \mathrm{sec}$ & 30 & $72^{\circ} \mathrm{C} 2 \mathrm{~min}$ \\
$\beta$-actin & $94^{\circ} \mathrm{C} 2 \mathrm{~min}$ & $94^{\circ} \mathrm{C} 30 \mathrm{sec}, 67^{\circ} \mathrm{C} 30 \mathrm{sec}, 72^{\circ} \mathrm{C} 30 \mathrm{sec}$ & 25 & $72^{\circ} \mathrm{C} 2 \mathrm{~min}$ \\
\hline
\end{tabular}

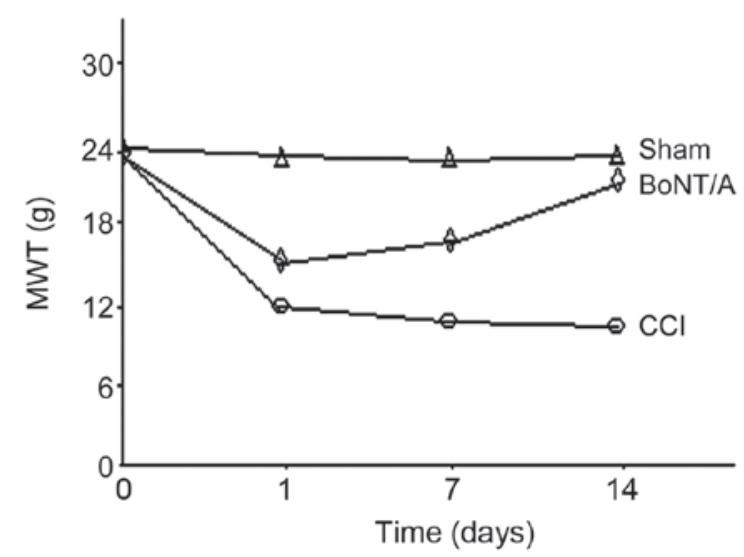

Figure 1. Mechanical withdrawal threshold (MWT) among groups. CCI, chronic constriction injury.

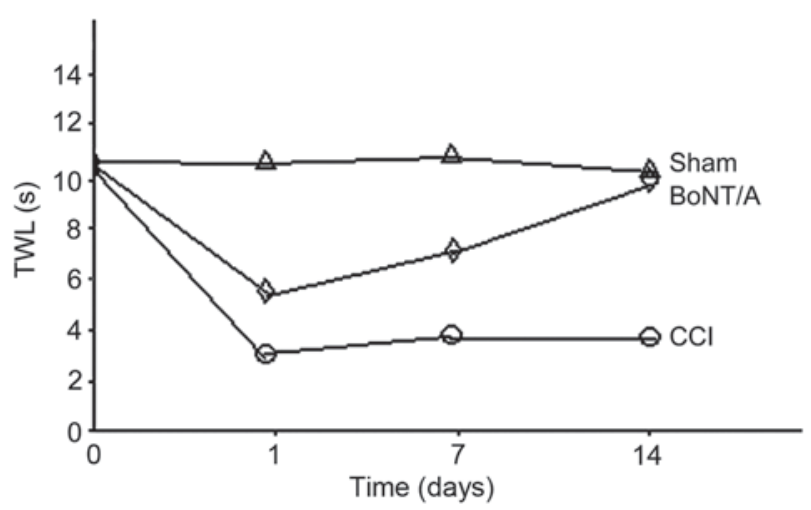

Figure 2. Thermal withdrawal latency (TWL) among groups. CCI, chronic constriction injury.

while the internal difference at each time point showed no statistical significance $(\mathrm{P}>0.05)$. MWT and TWL on the day after operation within the BoNT/A intervention group was clearly higher than that in the CCI group and lower than that in the sham-operated group, and the amount after 7 days was increased compared to the first day after operation. Further, it was consistent with that in the sham-operated group on day 14 after the operation, therefore, the difference of each time point had statistical significance $(\mathrm{P}<0.05)$ within the groups (Figs. 1 and 2).

Comparison of RT-PCR test index among groups. The expression levels of protein of SNAP-25 and NR2B mRNA in the CCI group were clearly higher than the sham-operated group. However, in the BoNT/A intervention group they were

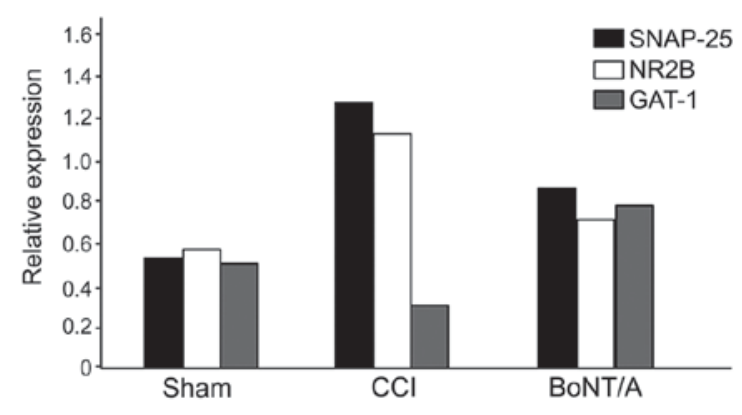

Figure 3. Detecting mRNA by RT-polymerase chain reaction. CCI, chronic constriction injury.

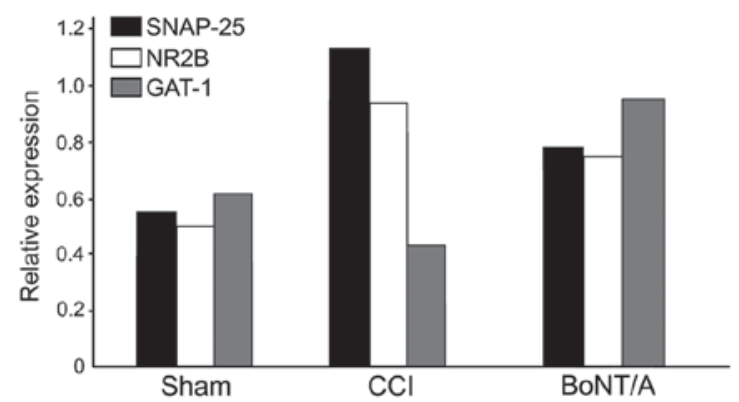

Figure 4. Detecting target protein through western blotting. CCI, chronic constriction injury.

comparatively lower than in the CCI group, but higher than the sham-operated group, thus, the differences had statistical significance $(\mathrm{P}<0.05)$. Additionally, the expression levels of GAT-1 mRNA and protein in the CCI group were apparently lower than that of the sham-operated group, and that in the BoNT/A intervention group was apparently higher than in the CCI and sham-operated groups. Thus, the differences had statistical significance $(\mathrm{P}<0.05)$ (Figs. 3 and 4$)$.

\section{Discussion}

SNAP-25 accounts for $1 \%$ of the total brain protein. Vesicle fusion complex is composed of two $\alpha$ helices with synyaxin-1 and synaptobrevin, anchoring on the cytoplasmic side of the cell membrane by palmitoyl located in the central region of the molecular structure (12). The main distribution of SNAP-25 is in the nerve terminals around the synapse, and some is also localized along the axon and dendrites of neurons (13). SNAP-25 regulates endocrine and the release of neurotransmitters. Moreover, it has a close relationship with regulatory proteins released by other synaptic vesicles, and 
calcium ion channels. For example, it plays an important part with initial protein transmitter, synaptotamin, in calcium ion initiation of membrane fusion mechanism and in cytokinetics regulating the last step of transmitter release (14). SNAP-25 is also able to regulate a variety of voltage-gated ion channels. Particularly, it could regulate voltage-gated calcium channels on non-neuronal cells, including SNAP-25 N, SNAP-25 P/Q, and SNAP-25 L channels (15). Therefore, SNAP-25 plays a key role in releasing neurotransmitters in the central nervous system.

BoNT/A has selective antitumor action on acetylcholine of nerve endings at neuromuscular junctions. BTXA could clinically be used to treat muscle tension and spastic disease, such as strabismus and torticollis (16). First, BTXA combines with receptors of the nerve cell, presynaptic membrane of the nerve cells, such as ganglion glycosides, synaptic vesicle protein 2, and synaptic binding protein, then BTXA adheres to the nerve cells and enters inside through the endocytosis mechanism. Finally, light chain of BTXA is endonuclease $\mathrm{Zn} 2^{+}$during the process of transferring from inside the vesicles to the cytoplasm (17). A large number of experiments in vitro and in vivo showed that (18), botulinum toxin could also inhibit the release of a variety of neurotransmitters, including glutamate, GABA, aspartate, catecholamines, dopamine and monoamine neurotransmitters (19-21). It could inhibit the release of glutamate from non-neural cells, such as astrocytes, and inhibited the release of substance P. All these neurotransmitters and neuropeptides are key signaling molecules in NPP.

In the present study, MWT and TWL after operation in the CCI group was obviously lower than the sham-operated group. Although the difference was statistically significant, it is of little significance when comparing the time points within each group. When NPP occurs, it reaches the maximum value, showing high sensitivity characteristics. Moreover, it did not increase or decrease with time. On day 1 after the operation MWT and TWL in the postoperative BoNT/A intervention group was significantly higher than that of CCI, but lower than the sham-operated group. Compared with that at day 7 , and that at day 1, it was significantly increased. At day 14 it was the same as that of the sham-operated group. Moreover, compared with each time point, the difference was statistically significant. Furthermore, lower concentration of BoNT/A could significantly improve the pain threshold and it relieved the pain with time. BoNT/A has a continuous effect. The expression level of SNAP-25 and NR2B, mRNA and protein of CCI were significantly higher than that of the sham-operated group. However, it was lower than that of CCI group and higher than the sham-operated group. These differences were statistically significant. mRNA GAT-1 and protein in CCI was significantly lower than the sham-operated group. Botulinum toxin type A reduced SNAP-25 and excitatory transmitters of rat sciatic nerve in the chronic pain model, thereby increasing the expression of inhibitory transmitter and resulted in easing of pain.

\section{References}

1. Suzuki T, Miyamoto K, Yokoyama N, Sugi M, Kagioka A, Kitao Y, Adachi T, Ohsawa M, Mizukami H and Makino T: Processed aconite root and its active ingredient neoline may alleviate oxaliplatin-induced peripheral neuropathic pain J Ethnopharmacol 186: 44-52, 2016.
2. Hepner S and Claxton R: Anti-epileptic drugs for pain \#271. J Palliat Med 16: 799-800, 2013.

3. Takura T, Shibata M, Inoue S, Matsuda Y, Uematsu H, Yamada K and Ushida T: Socioeconomic value of intervention for chronic pain. J Anesth 30: 553-561, 2016.

4. Guillemyn K, Starnowska J, Lagard C, Dyniewicz J, Rojewska E, Mika J, Chung NN, Utard V, Kosson P, Lipkowski AW, et al: Bifunctional peptide-based opioid agonist - nociceptin antagonist ligands for dual treatment of acute and neuropathic pain. J Med Chem 59: 3777-3792, 2016.

5. Kahle KT, Schmouth JF, Lavastre V, Latremoliere A, Zhang J, Andrews N, Omura T, Laganière J, Rochefort D, Hince P, et al: Inhibition of the kinase WNK1/HSN2 ameliorates neuropathic pain by restoring GABA inhibition. Sci Signal 9: ra32, 2016.

6. Liu C, Guo QL, Huang CS, Zou WY and Song ZB: Suppressing SNAP-25 and reversing glial glutamate transporters relieves neuropathic pain in rats by ameliorating imbalanced neurotransmission. Chin Med J (Engl) 126: 4100-4104, 2013.

7. Zeng J, Cui LY, Feng Y and Ding MX: Electroacupuncture relieves neuropathic pain via upregulation of glutamate transporters in the spinal cord of rats. Neurosci Lett 620: 38-42, 2016.

8. Yadav R, Yan X, Maixner DW, Gao M and Weng HR: Blocking the GABA transporter GAT-1 ameliorates spinal GABAergic disinhibition and neuropathic pain induced by paclitaxel. $J$ Neurochem 133: 857-869, 2015.

9. Oh HM and Chung ME: Botulinum toxin for neuropathic pain: A review of the literature. Toxins (Basel) 7: 3127-3154, 2015.

10. Luvisetto S, Gazerani P, Cianchetti C and Pavone F: Botulinum toxin type a as a therapeutic agent against headache and related disorders. Toxins (Basel) 7: 3818-3844, 2015.

11. Bennett GJ, Nishikawa N, Lu GW, Hoffert MJ and Dubner R: The morphology of dorsal column postsynaptic spinomedullary neurons in the cat. J Comp Neurol 224: 568-578, 1984.

12. Lu B: The destructive effect of botulinum neurotoxins on the SNARE protein: SNAP-25 and synaptic membrane fusion. Peer J 3: e1065, 2015.

13. Hussain S, Ringsevjen H, Egbenya DL, Skjervold TL and Davanger S: SNARE protein Syntaxin-1 colocalizes closely with NMDA receptor subunit NR2B in postsynaptic spines in the hippocampus. Front Mol Neurosci 9: 10, 2016.

14. Carbone E, Calorio C and Vandael DH: T-type channel-mediated neurotransmitter release. Pflugers Arch 466: 677-687, 2014.

15. Condliffe SB, Fratangeli A, Munasinghe NR, Saba E, Passafaro M, Montrasio C, Ferrari M, Rosa P and Carrera P: The E1015K variant in the synprint region of the CaV2.1 channel alters channel function and is associated with different migraine phenotypes. J Biol Chem 288: 33873-33883, 2013.

16. Climent JM, Kuan TS, Fenollosa P and Martin-Del-Rosario F: Botulinum toxin for the treatment of myofascial pain syndromes involving the neck and back: A review from a clinical perspective. Evid Based Complement Alternat Med 2013: 381459, 2013.

17. Marinelli S, Vacca V, Ricordy R, Uggenti C, Tata AM, Luvisetto S and Pavone F: The analgesic effect on neuropathic pain of retrogradely transported botulinum neurotoxin A involves Schwann cells and astrocytes. PLoS One 7: e47977, 2012.

18. Mustafa G, Anderson EM, Bokrand-Donatelli Y, Neubert JK and Caudle RM: Anti-nociceptive effect of a conjugate of substance $\mathrm{P}$ and light chain of botulinum neurotoxin type A. Pain 154: 2547-2553, 2013.

19. Verderio C, Grumelli C, Raiteri L, Coco S, Paluzzi S, Caccin P, Rossetto O, Bonanno G, Montecucco C and Matteoli M: Traffic of botulinum toxins $\mathrm{A}$ and $\mathrm{E}$ in excitatory and inhibitory neurons. Traffic 8: 142-153, 2007.

20. Drinovac V, Bachrojecky L and Lacković Z: Association of antinociceptive action of botulinum toxin type A with GABA-A receptor. J Neural Transm (Vienna) 121: 665-669, 2014.

21. Habermann E: Inhibition by tetanus and botulinum A toxin of the release of $[3 \mathrm{H}]$ noradrenaline and $[3 \mathrm{H}] \mathrm{GABA}$ from rat brain homogenate. Experientia 44: 224-226, 1988. 